\title{
Development of a new self-powered electrochromic device for light modulation without external power supply
}

\author{
C. Bechinger*, B.A. Gregg \\ National Renewable Energy Laboratory, 1617 Cole Blvd., Golden, CO 80401-3393, USA
}

\begin{abstract}
Despite considerable improvements within the last decades, electrochromic (EC) window coatings are still too expensive to be applied in buildings on a large scale. Beside the manufacturing costs, wiring costs have to be added which may exceed the fabrication expenses of the electrochromic window. Therefore, self-powered electrochromic windows have been considered, where a semi-transparent photovoltaic $(\mathrm{PV})$ cell provides the power to activate an electrochromic system deposited on top of the solar cell. The whole PVEC device consists of up to eight layers which must be deposited on large scales without short circuits or other failures. Recently, we came up with a much simpler idea where power generation and electrochromic properties are combined rather than just added as in the case of the PVEC cell. The whole device now is obtained by the deposition of only three layers and is highly transparent in the bleached state. Exposing it to sunlight and completing an external circuit the device can be colored within a few minutes, reducing the transmission by about $40 \%$. Bleaching occurs either spontaneously by blocking the sunlight or is induced by a small rechargeable battery which can be incorporated in the external circuit and is charged from the device when exposed to sunlight. (C) 1998 Elsevier Science B.V. All rights reserved.
\end{abstract}

Keywords: Electrochromism; Photovoltaics

\footnotetext{
* Corresponding author. permanent address: Universität Konstanz, Fach M675, D-78457 Konstanz, Germany. E-mail: clemens.Bechinger@uni-Konstanz.de
} 


\section{Introduction}

Thin films of many transition metal oxides are well known to exhibit electrochromic (EC) properties which can be used for devices with variable optical transmittance or reflectance. Within the last $30 \mathrm{y}$ the feasibility of numerous potential EC devices like window coatings [1,2], variable mirrors [2], large area displays [3], photo-imaging systems [4-6] and more have been demonstrated. All those devices take advantage of the optical transition of an EC thin film which is induced when metal ions $\left(M=\mathrm{H}^{+}, \mathrm{Li}^{+}, \mathrm{Na}^{+} \ldots\right)$ and electrons are injected or extracted by a small voltage. In case of tungsten oxide $\left(\mathrm{WO}_{3}\right)$ being the most common representative of $\mathrm{EC}$ materials and $\mathrm{Li}^{+}$as the used ion, this process can be written as [7]

$$
\text { (transparent) } \quad \mathrm{WO}_{3}+x \mathrm{Li}^{+}+x \mathrm{e}^{-} \leftrightarrow \mathrm{Li}_{x} \mathrm{WO}_{3} \quad \text { (colored) }
$$

Electrochromic devices can be constructed in several different ways, all of which can be viewed as variations of the following basic design: Several layers are backed by a substrate (glass or plastic), which is covered with a transparent conducting layer, followed by an EC layer, a fast ion conductor or electrolyte, a layer serving as ion storage-and a second (transparent) conductor. The electrochromic and ion storage films are mixed conductors for ions and electrons, whereas the ion conductor ideally should have zero conductivity for electrons. When a voltage is applied between the transparent conductors, ions will be driven into or out of the electrochromic film, corresponding to Eq. (1). The process is highly reversible and can be repeated several 10000 times [8].

The optical change of an EC device affects both, the visible and the near infrared part of the spectrum. Therefore, EC window applications have - besides an increase in comfort - also the potential of lowering cooling costs of those buildings. In the United States alone, presently there exist approximately 2 billion $\mathrm{m}^{2}$ of windows in commercial and residential buildings culminating in enormous cost and energy demands for air conditioning to negate unwanted solar heat gains through these windows. Detailed simulations of building thermal performance indicate that an EC window coating, operating with an appropriate control strategy, will significantly reduce the power consumption for air conditioning and heating $[9,10]$.

The energetical benefit of smart windows would be even amplified if self-powered EC systems would be used which do not depend on an external power supply. It has been demonstrated that a semitransparent $\mathrm{a}-\mathrm{SiC}: \mathrm{H}$ widegap photovoltaic $(\mathrm{PV})$ cell on top of an EC device can provide the electrical power required for operation [11]. Such a PV/EC device consists of eight sequentially evaporated layers that must be extremely thin for the device to be semitransparent. Unfortunately, electrical shorts in the PV cells are a serious problem which may impede the fabrication of large-area devices [12].

In this paper, we suggest a new self-powered EC system based on integrating electrochromic films with dye-sensitized photoelectrochemical (PEC) cells $[13,14]$. Due to the high compatibility of those technologies [15] - both rely on redox couples and widegap semiconductors on transparent conducting substrates - both properties can be integrated in a single device (PECEC). In contrast to the PV/EC device which 
just adds the complexity of a photovoltaic and an EC structure the PECEC cell rather integrates the two structures in a single device, which essentially consists of three layers. This is achieved by internal coupling of the PEC cell and the EC layer by a redox reaction rather than by an electrical contact.

\section{Experimental}

The basic structure of the experimental photoelectrochemical-electrochromic (PECEC) cell used in this work is schematically shown in Fig. 1. The light-absorbing function in the device is performed by a dye-sensitized semiconductor electrode that produces a photovoltage sufficient to color the electrochromic film. The PEC electrode used in this work, consists of a $\mathrm{TiO}_{2}$ electrode being sensitized with a ruthenium polypyridine complex similar to those introduced by Grätzel et al. for use in solar cells. A thin film of $\mathrm{WO}_{3}$ was used as the counter electrode.

A $4 \mu \mathrm{m}$ thick nanocrystalline $\mathrm{TiO}_{2}$ was deposited by roll-coating onto a $\mathrm{SnO}$ coated glass substrate and then fired for $30 \mathrm{~min}$ at $470^{\circ} \mathrm{C}$. Then the dye, $\mathrm{Ru}(\mathrm{II}) \mathrm{L}_{2} \mathrm{~L}^{\prime}$, where $\mathrm{L}=2,2^{\prime}$ - bipyridine-4,4'- dicarboxylate and $\mathrm{L}^{\prime}=4,4^{\prime}$ - dimethyl-2,2' - bipyridine, was adsorbed onto the $\mathrm{TiO}_{2}$ film from a dilute $(8 \mu \mathrm{M})$ ethanol solution containing $30 \mathrm{mM}$ chenodeoxycholic acid $[13,14]$. The dye coverage was kept low to make the cells almost transparent in the "off" state. The coadsorbate, chenodeoxycholic acid, was used to increase the photocurrent efficiency [16]. The counterelectrode was prepared by thermal evaporation of $500 \mathrm{~nm} \mathrm{WO}_{3}$ onto an indium-tin oxide coated

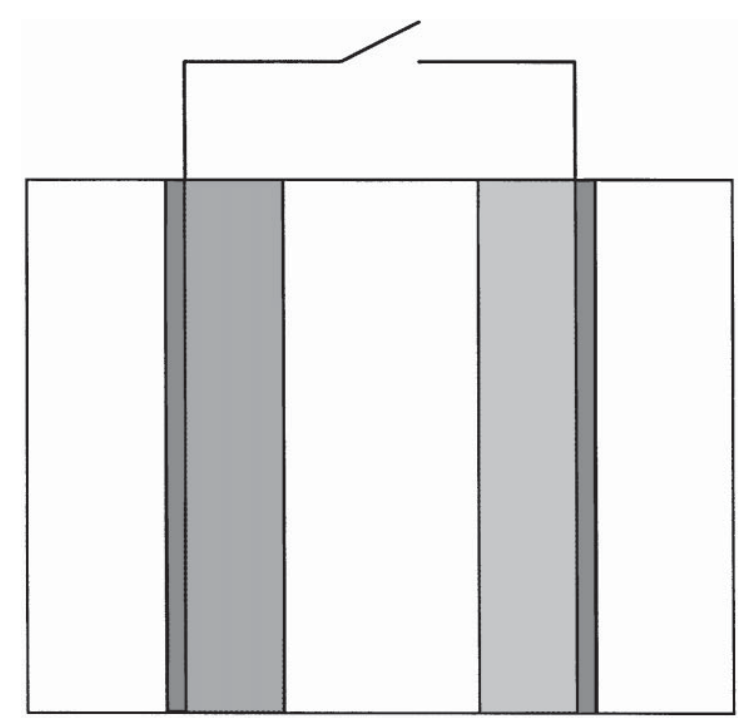

Fig. 1. Schematic drawing of our PECEC device. From the left to the right: glass substrate, ITO, dye-sensitized $\mathrm{TiO}_{2}$ electrode, electrolyte, $\mathrm{WO}_{3}$ counterelectrode, ITO, glass substrate. 
glass substrate. Then the two electrodes were bonded to each other around their periphery with $30 \mu \mathrm{m}$ thick strips of Surlyn 1601 . As electrolyte we used propylene carbonate containing $0.1 \mathrm{M}$ LiI and $0.01 \mathrm{M}$ tert-butylpyridine which was filled through small holes drilled in the $\mathrm{WO}_{3}$ electrode. The fill holes were then sealed with epoxy cement. Cells were fabricated ranging in size from 1 to $25 \mathrm{~cm}^{2}$.

\section{Results and discussion}

Fig. 2 shows the typical response of the transmittance of a PECEC device with connected terminals when subjected to a light source (intensity about 1 sun) which is chopped very slowly. The relative change of the obtained transmission changes probed at a wavelength of $788 \mathrm{~nm}$ is in the order of $70 \%$. After the light is turned on the transmission decreases and reaches its saturation level after about $100 \mathrm{~s}$ almost. After blocking the white light with a shutter, spontaneous bleaching is observed which leads back to the original state within less than $200 \mathrm{~s}$. The open-circuit voltage of this device in the bleached state upon exposure to 1 sun was $880 \mathrm{mV}$.

Upon light exposure of the device the dye injects electrons into the highly porous $\mathrm{TiO}_{2}$ film which is followed by re-reduction of the oxidized dye via electron transfer due to the reaction of iodide $\left(\mathrm{I}^{-}\right)$to iodine $\left(\mathrm{I}_{3}^{-}\right)$. At open-circuit conditions, this produces a photovoltage of $0.6-0.9 \mathrm{~V}$ but does not result in coloration of the device. When the electrodes are shorted, however, the electrons move from the $\mathrm{TiO}_{2}$ through the external circuit to the $\mathrm{WO}_{3}$ film and the electrolyte is charged positively. This forces $\mathrm{Li}^{+}$ions from the electrolyte also to be inserted into the tungsten oxide counter electrode which according to Eq. (1) finally causes the reaction leading to coloration of $\mathrm{WO}_{3}$. Upon blocking the light the process is reversed which results in bleaching of

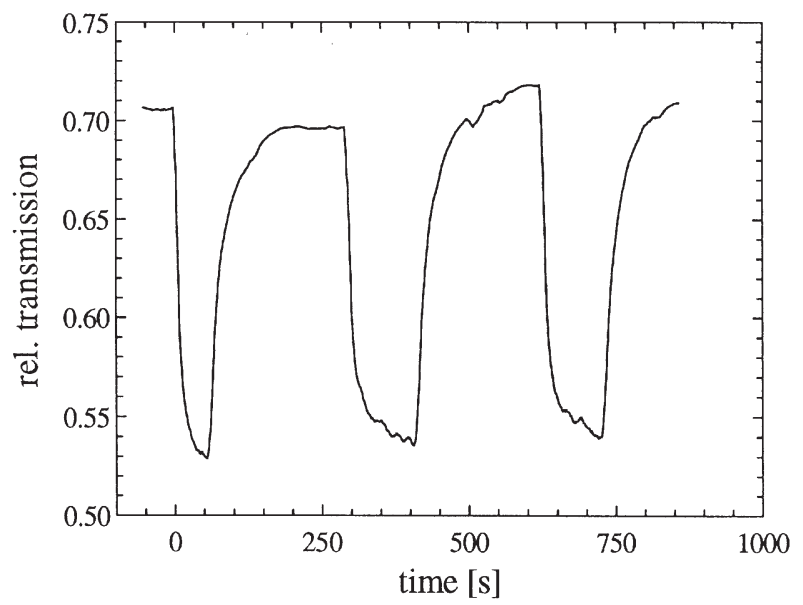

Fig. 2. Relative transmission change of shorted PECEC device upon exposure to chopped light (intensity about one sun). 
the $\mathrm{WO}_{3}$ electrode. Coloration and bleaching is similar to the charging and decharging cycle of a battery where in this particular case the color of the $\mathrm{WO}_{3}$ electrode can be considered as a charge indicator. Under illumination the dye-sensitized $\mathrm{TiO}_{2}$ electrode produces an electrical voltage $V_{\mathrm{OC}}$ which (in case of connected terminals) causes the $\mathrm{WO}_{3}$ layer to be "charged" with $\mathrm{Li}^{+}$ions. The accumulation of lithium ions in the $\mathrm{WO}_{3}$ electrode gives rise to an electrochemical potential of opposite direction, which finally reaches $-V_{\mathrm{OC}}$. In this situation the total voltage between the terminals is zero and one obtains deepest coloration. When the light is turned off and the solar cell is no longer producing an electrical voltage, the total voltage between the terminals is $-V_{\mathrm{OC}}$. This causes the $\mathrm{WO}_{3}$ to be "discharged" from $\mathrm{Li}^{+}$and electrons and leads back to the bleached original state. From the above it is obvious that a high photovoltage of the solar cell is important for fast coloration.

Since ion migration across the electrolyte is required for electrochromism, in case of a very thin electrolyte layer, where the lateral ion conductivity is small, spatially resolved coloration can be obtained when just part of the device is illuminated. Once the ions are intercalated into the $\mathrm{WO}_{3}$ film, their lateral mobility becomes so small that an image can be stored for many hours. Photographs of a $25 \mathrm{~cm}^{2}$ cell in bleached, colored and inhomogeneously colored states are shown in Fig. 3 a-c. With an electrolyte thickness above $1 \mathrm{~mm}$ always a homogeneous coloration is obtained even if only a part of the device is exposed to sunlight. The latter might be useful for window applications whereas structured coloration might be useful for image storage applications.

The use of a PEC cell has some important advantages over the more common inorganic semiconductor PV cells when use in a self-powered EC device: The lightabsorbing layer can be made optically thin by either reducing the thickness of the $\mathrm{TiO}_{2}$ layer or by decreasing the concentration of the dye. Furthermore, it is possible,

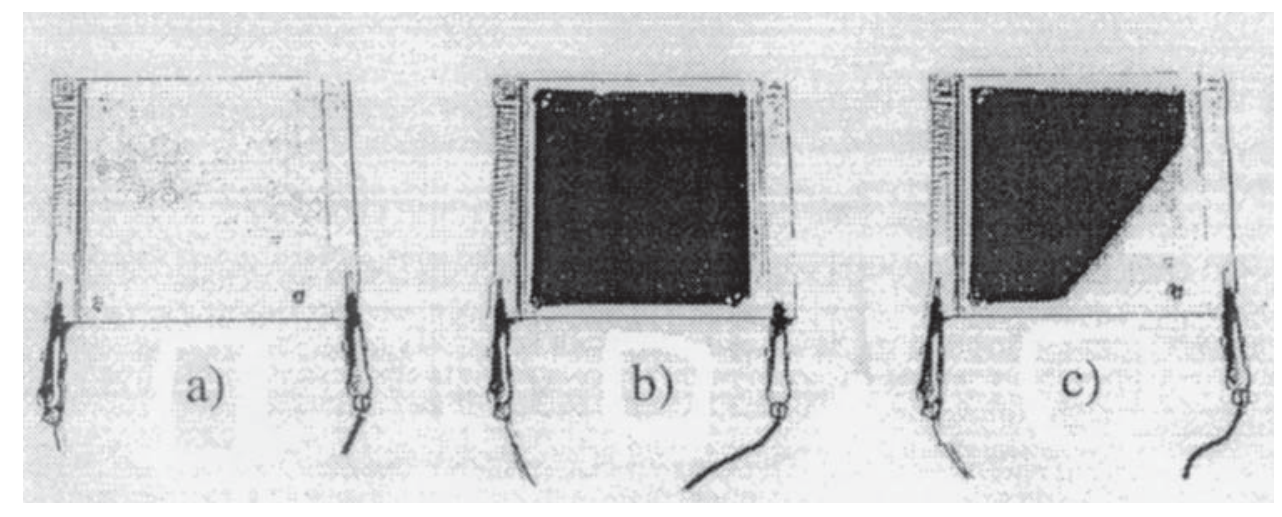

Fig. 3. Photographs of PECEC device with a $25 \mathrm{~cm}^{2}$ active area. The bleached state (a) is light yellow due to the sensitizing dye and some adsorption and scattering from the $\mathrm{TiO}_{2}$ and $\mathrm{WO}_{3}$ electrodes. The uniformly colored state (b) achieved by illumination at one sun intensity for $1 \mathrm{~min}$. The inhomogeneously colored state (c) achieved by illumination with one corner of the cell masked. The states shown in (b) and (c) remain approximately unchanged for at least $24 \mathrm{~h}$ if the cell is kept at open circuit. 
in principle, to use an infrared sensitizing dye so the entire device is transparent to visible light in the "off" state.

It is difficult to estimate the lifetime of a PECEC device. Tightness of the cells was in our case the most serious problem which caused device failure after about 3 months and several hundreds of cycles. However, since a PECEC device is very similar to a dye-sensitized solar cell our device will benefit from the rapid technical improvements (e.g. in the field of cell tightening) in this area.

\section{Conclusions}

Our results demonstrate that dye-sensitized solar cells and EC cells can be easily combined. Due to the high compatibility of those technologies - both rely on redox couples and widegap semiconductors on transparent conducting substrates - both properties can be integrated in a single device. In contrast to the PV/EC device which just adds to the complexity of a photovoltaic and an EC structure the PECEC cell rather integrates the two structures in a single device without essentially increasing its complexity. This is achieved by internally coupling the solar cell and the EC layer by a redox reaction rather than by an electrical contact.

\section{Acknowledgements}

We thank S. Ferrere, A. Zaban and J. Sprague for technical assistance and helpful discussions and the U.S. Department of Energy for funding this research. C.B's. work was also supported by the Deutsche Forschungsgemeinschaft.

\section{References}

[1] C.G. Granqvist, Sol. State Mater Sci. 16 (1990) 291.

[2] S.K. Deb, Sol. Energy Mater Sol. Cells 25 (1992) 327.

[3] M. Green, W.C. Smith, J.A. Weiner, Thin Solid Films 38 (1976) 89.

[4] M. Shizukuishi, I. Shimizu, E. Inoue, Jpn. J. Appl. Phys. 20 (1981) 2359.

[5] M. Nagasu, N. Koshida, Appl. Phys. Lett. 57 (1990) 1324.

[6] S.K. Deb, Appl. Opt. Suppl. 3 (1969) 192.

[7] B.W. Faughnan, R.S. Crandall, P.M. Heyman, RCA Rev. 36 (1975) 177.

[8] S.F. Cogan, R.D. Rauh, in SPIE IS4 (1990) p. 482.

[9] D.K. Benson, H.M. Branz, Sol. Energy Mater Sol. Cells 39 (1995) 203.

[10] B. Hichwa, J.G.H. Mathew, N.O. Brian, V. Raksha, S.P. Sapers, S. Sullivan, L. Wang, in: Fall Meeting of the Electrochemical Society, vol. 95(2), Chicago, IL, 1995, p. 942.

[11] C. Bechinger, J.N. Bullock, J.-G. Zhang, C.E. Tracy, D.K. Benson, S.K. Deb, H.M. Branz, J. Appl. Phys. 80 (1996) 1226

[12] J.N. Bullock, C. Bechinger, Y. Xu, D.K. Benson, H.M. Branz, in: MRS, San Francisco, CA, 1996.

[13] B. O'Regan, M. Grätzel, Nature 353 (1991) 737.

[14] M.K. Nazeeruddin, A. Kay, I. Rodicio, R. Humphry, E. Müller, P. Liska, N. Vlachopoulos, M. Grätzel, J. Am. Chem. Soc. 115 (1993) 6382.

[15] C.M. Lampert, Sol. Energy Mater Sol. Cells 32 (1994) 307.

[16] A. Kay, M. Grätzel, J. Phys. Chem. 97 (1993) 6272. 